\title{
Automatic Detection and Correction the Fault in Electrical Power Feeders Based Microcontroller
}

Jahlool JS*

Computer Technique's Engineering Department, Dijlah University College, Baghdad, Iraq

\begin{abstract}
One of the problems repeated by homes is a malfunction in one or more than one of three main electrical power feeders (3MEPF) 3-phase, and this fault is caused by a cut or weakness in that feeders AC voltage. In this paper, a proposed design was developed and implemented to automatically address this problem by reading and checking constantly the level of voltages of the three feedings AC voltage supply. If the voltages level of one or more of these feeders are cut or below the required voltage level to operate the home appliances, the machine performs at the same time three operations. First, sends an alert SMS message to mobile home owner by using global system of mobile (GSM) communications networks to tell him there is a defect in the feeder voltage with limited the number and type of defect (cut or weak). Second the machine automatically changes the electric power supply from weak or cut feeder to the adjacent right feeder. There'd display at liquid crystal device (LCD) the type of defect and the feeding name. The instrument's used to implement this design are PIC microcontroller type 18F45K22 with software type (mikroC PRO for PIC), GSM modem type SIM800L, 16x2 LCD and in addition to relays, transformers, capacitors, resistors, and ULN2003 drivers. The design will be implemented and tested at below figures respectfully.
\end{abstract}

Keywords: Fault detect; GSM modem; Microcontroller; mikroC; Power feeder

\section{Introduction}

The general trend in research and electronic design is to choice of the best automatic techniques to continuity of supply the electric power and reduce the losses in the field of electric power consumption by homes, office and others places, as well as to find best solutions without human interference or to reduce him intervention and thus provide an economy in time, cost and effort. Most of these solutions is depend on GSM networks to send information and instructions, as well as the use of automatic circuits and electronic voltage or current sensors. One such application can be using for control of home 3MEPF, which results in effective and efficient use of electrical power and reducing the loss. The faults that occur in the power supplly sources for homes occur all over the world. Therefore, this proposed system take this opportunity to put forward a cost effective method for automatically switching to right $3 \mathrm{MEPF}$. This leads to the continuity of processing the electrical power of all the devices of houses without period of stopping. Detection multiple event, recognition and temporal localization in large scale power system and him propose a new method for achieve this reason defined as cluster based sparse coding [1]. System to detect the theft of electricity in all known or common methods which are done by Exceeding the meter by attaching the power supply cable before the meter and the method used is to install a concealed system inside the counters which sends a text message to the control unit from the power panel [2]. A user can fault and switch detection of the electrical devices or appliances by using android type of mobile, using the IOT, GSM \& Wi-Fi [3]. Fault detection system will be generated that helps the operators to fast identify a fault presence and the location of it. In this paper the work is composed by two steps. To do the fault detection this is the first step by using fuzzy logic system, while second step is sued to gives the final diagnosis measuring the Euclidean distance between the voltages of the lines for each mode [4]. classification of fault detect approaches in the power system will be explain [5]. Over current and under voltage detection method are presented and implemented by using voltage and current sensor as a fault detection unites [6]. In this proposed paper using a new simple and low cost method to continuity of detection and reading the weak or cut one or more than on of the home $3 \mathrm{MEPF}$ and when detected it is automatic transfer to the right feeder and inform the home owner by GSM sms message tell him the feeder fault or cut number and the number of new right feeder which converted to it.

\section{Description Strategy the Proposed System}

The block diagram of proposed system is shown in the Figure 1. It is an outline description of how implemented the proposed design and the main components involved in it.

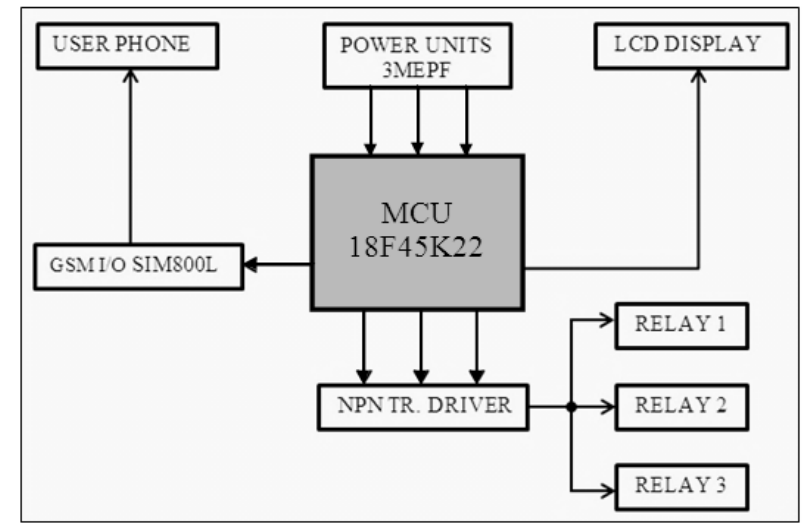

Figure 1: Proposed system block diagram.

*Corresponding author: Jahlool JS, Computer Technique's Engineering Department, Dijlah University College, Baghdad, Iraq, Tel: 009647724109262; E-mail: Jabbar.shatti@duc.edu.iq

Received May 07, 2018; Accepted June 30, 2018; Published July 07, 2018

Citation: Jahlool JS (2018) Automatic Detection and Correction the Fault in Electrical Power Feeders Based Microcontroller. J Electr Electron Syst 7: 271. doi: 10.4172/2332-0796.1000271

Copyright: ( 2018 Jahlool JS. This is an open-access article distributed under the terms of the Creative Commons Attribution License, which permits unrestricted use, distribution, and reproduction in any medium, provided the original author and source are credited. 
Citation: Jahlool JS (2018) Automatic Detection and Correction the Fault in Electrical Power Feeders Based Microcontroller. J Electr Electron Syst 7: 271. doi: $10.4172 / 2332-0796.1000271$

Page 2 of 6

The system block diagram below clearly shows the design depend on using $18 \mathrm{~F} 45 \mathrm{~K} 22$ microcontroller (MCU) as a central unit to accessing all system equipment's, Initially the MCU read and test all $3 \mathrm{MEPF}$, when there is a malfunction, whether it is a cut or a weakness in one or more of these feeders voltages, the MCU will automatically generates a signal indicating that situation and sends it at the same time to three directions.

First to GSM I/O modem to rephrases this event in the form of a text message (simple SMS message) that send to the owner cellular phone via global system for mobile (GSM), this SMS message alert the owner that there is a one or more than one feeding fault (weak or cut) and also tell him about transformation of the electric power supply of right feeder instead of fault feeder. Second direction sends to $16 \times 2 \mathrm{LCD}$ to display the status of the three feeders. Finally the third direction sends to a relay via the NPN transistor driver for the purpose of converting from the fault feeder to the right feeder. This process is repeated over time for the purpose of maintaining continuously, safely and ensuring work of the appliances through the electric power supply. This way leads to reduce the damage at home appliances due to imbalance in the source of power supply and ensure the safety of work without accidents.

\section{System Flow Chart}

The algorithm approach to the proposed system shows the continuity for testing and monitors the (3MEPF) A.C 220 volt phases this part of design has implemented through working of MCU program. Figure 2 shows the flow chart of main operation steps for proposed system algorithm. The system decision starts when it detects any defect (cut or weak) in one feeder or more. The system operational written by mikroC PRO for PIC program.

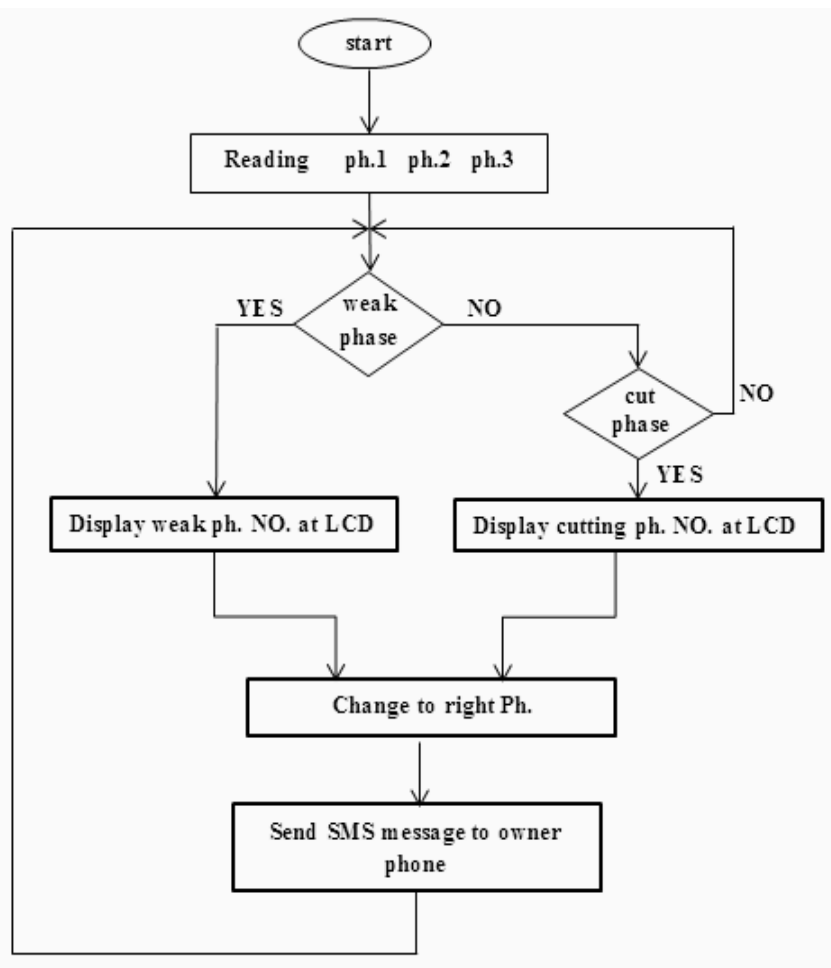

Figure 2: Proposed system flow chart.

\section{Details Mains System Components}

In this section, describe and explain some of important system components used in the prototype and simulation design, take in other consideration not to describe the specifications of the simple parts such as resistors, capacitances and diodes because they are clear in the circuit diagram of the system.

\section{Microcontroller PIC18F45K22}

This MCU represents one of the latest products from microchip MCUs, therefor was chosen for this design because it has important features like low prices, wide range of application, high quality and easy availability, it is an ideal solution in applications like the control of different processes in industry, machine control devices, measurement of different values because have (17) inputs analog channels and 10bit resolution analog to digital converters (ADC), which invested three channels for proposed design system (AN0, AN1, AN2).

\section{GSM module SIM800L}

For the purpose of sending alert signal to the mobile of the home owner through the GSM network, this type is used to accomplish this task Figure 3.

In addition to its ability to compatible with mobile networks operating in Iraq, it is contains the key features shown in the Table 1 [7]. Also its size is so convenient that it is easy used as plug in GSM Modem. The Modem is designed to interface with the 5V DC TTL and $3 \mathrm{~V} 3$, this allows users to easily interface with $5 \mathrm{~V}$ MCUs (PIC, AVR, Arduino, 8051, etc) as well as 3V3 MCUs (ARM, ARM Cortex XX,

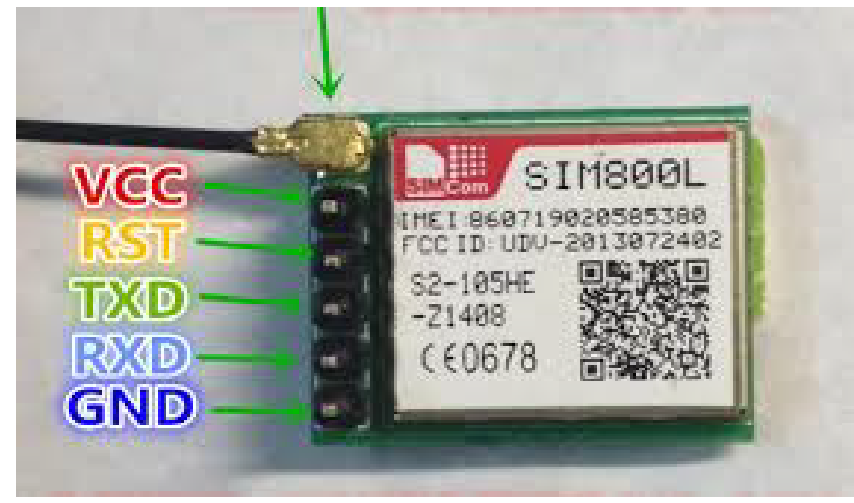

Figure 3: GSM Module SIM800L.

\begin{tabular}{|c|c|}
\hline Feature & Implementation \\
\hline Power supply & $3.4 \mathrm{~V}-4.4 \mathrm{~V}$ \\
\hline Power saving & $\begin{array}{l}\text { typical power consumption in sleep mode is } 0.7 \mathrm{~mA} \\
\left(\mathrm{AT}+\mathrm{CFUN}^{*}\right)\end{array}$ \\
\hline Frequency bands & $\begin{array}{l}\text { - Quad-band: GSM } 850 \text {, EGSM } 900 \text {, DCS } 1800 \text {, PCS } \\
\text { 1900. SIM800L can search the } 4 \text { frequency bands } \\
\text { automatically. The frequency bands can also be set by } \\
\text { AT command "AT+CBAND". For details, please refer to } \\
\text { document [I]. } \\
\text { - Compliant to GSM Phase } 2 / 2+\end{array}$ \\
\hline Transmitting power & $\begin{array}{l}\text { - Class } 4(2 \mathrm{~W}) \text { at GSM } 850 \text { and EGSM } 900 \\
\text { - Class } 1(1 \mathrm{~W}) \text { at DCS } 1800 \text { and PCS } 1900 \\
\text { - GPRS multi-slot class } 12 \text { ( default ) }\end{array}$ \\
\hline GPRS connectivity & GPRS multi-slot class 1-12 (option) \\
\hline Temperature range & Normal operation: $-40^{\circ} \mathrm{C}-+85^{\circ} \mathrm{C}$ \\
\hline
\end{tabular}

Table 1: SIM800L key features. 
etc.). Have a wide range of a baud rate can be from 9600 - 115200 bps (bit per second) through AT (Attention commands). It is suitable for SMS as well as DATA transfer application in mobile phone to mobile phone interface.

\section{System Implementation and Simulation}

It is important first to ensure that the hardware part of the proposed design working carefully and also to enable for interfacing the two parts (software and hardware). This is done by using simulation software to design and test all hardware parts for the purpose of ensuring the work of all parts of the system as carefully planning and to remedy the defects if any and find appropriate solutions, finally, transition to the physical connection in order to ensure the purpose for which it was designed. For this purpose the proteus professional design suit simulation program are used for hardware design implementation and mikroC PRO for PIC software for software implementation and downloading the main program. The proposed simulated circuit diagram shown in the Figure 4.

An important point should be noted in prototype design only of the above circuit, the same 220 volt electrical source input are used to feed the three feeders, and use three selector switch's to get different A.C source level from zero to 220 volt in order to examining all fault or weak possibilities. The output of each selector switch are connected to $220 / 12$ volt step down transformer and then to bridge rectifier then to filter capacitor to change the input feeder voltage from 220 volt A.C supply to 12 volt DC, each of this three DC voltages will be connected to three analog to digital (ADC) channels of MCU (RA0, RA1, RA2). Logically, any change in alternating input A.C voltages to the transformer, whether this change is weak or cut, that may control by the selector switch results in the same manner a change in the DC voltage that can be measured by MCU program and a decision will be taken on the nature of the work of the feeder under test if it is normal, the electric power supply continue to equip without work any think. While if there is a weakness or a cut it is converted to the right adjacent feeder this is done automatically by sending a signal to external relays connected to MCU pins ( $\mathrm{RC}, \mathrm{RC} 1$ and $\mathrm{RC} 2$ ) through a driver transistor. This process is performed on the three feeders. It should not be forgotten that there are other two direction for the output of the decision, first, in any case and at the same time the MCU will send a warning signal to the GSM I/O SIM800L which in turn releases a text message to the mobile phone of the home owner tell him the number of feeder and the type of fault (cut or weak). Second, the all information about the decision will be send to LCD connected to the MCU pins (RB0 to RB5) to display the status of all three feeders.

\section{Different Operation Cases}

The following Figures 5 and 6, respectively, show different cases of system operation.

\section{Case one}

When two feeders working normally while the there'd is weak this case and all cases controlled by selector switches. As shown in Figure 5.

\section{Case two}

When the first feeder is cut, second feeders work normally and there'd is weak. As shown in Figure 6.

\section{Physical Implementation of the Proposed System}

The Figures 7 and 8 below shows the final physical implementation of the circuit prototype and the printed board. Figure 9 showes sample of working case. Figure 10 showes sample of SMS messages send to home owner.

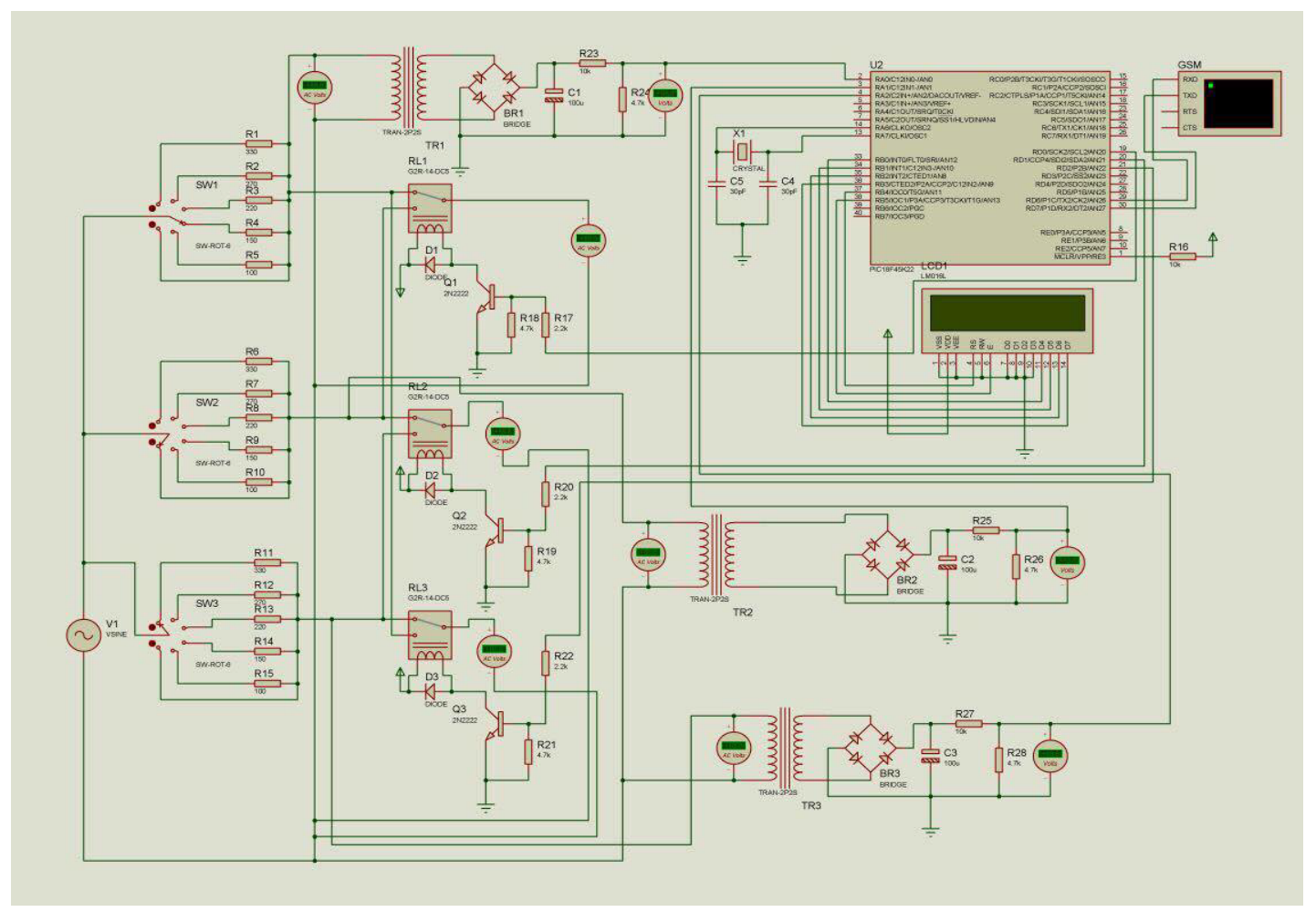

Figure 4: Proposed circuit diagram. 


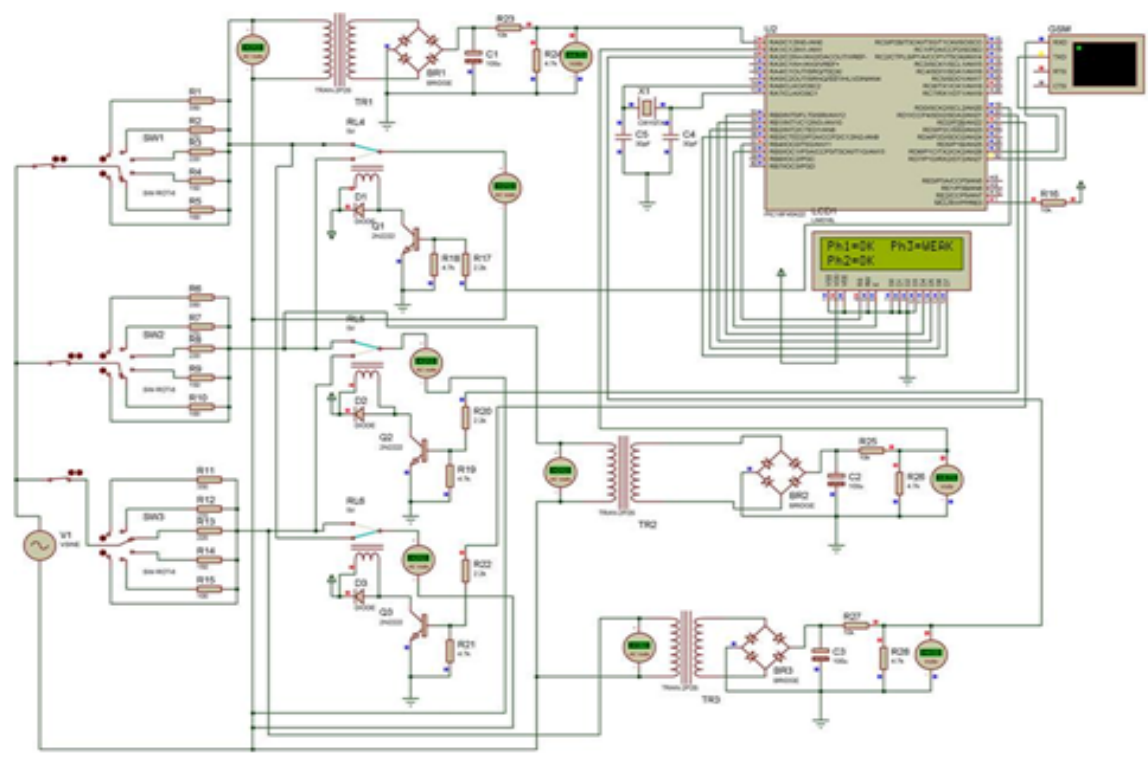

Figure 5: Simulation circuit diagram for case one working system.

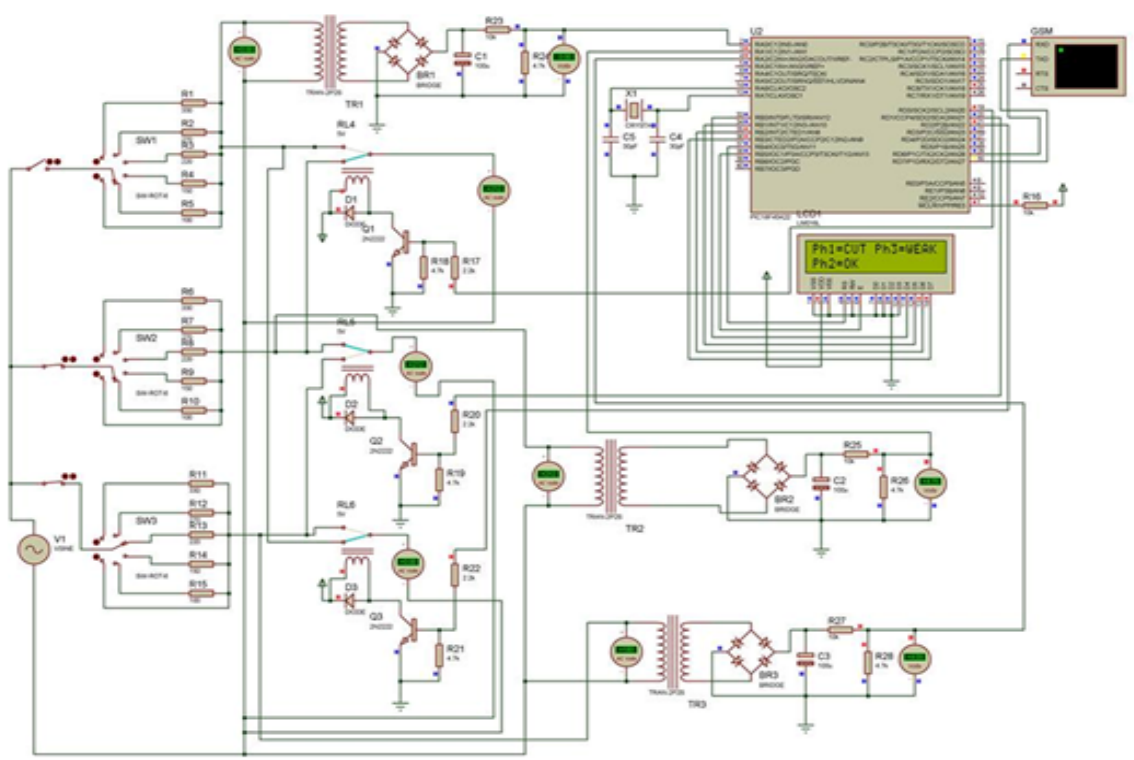

Figure 6: Circuit diagram for case two working system.

Sample of working cese shown in the LCD display of Figure 9. $\mathrm{Ph} .1 \mathrm{ok}, \mathrm{Ph} .2$ weak and Ph. 3 ok. The final working case as shown in the digital indicators to indicate that the weaking phase 2 . will automatically change to right feeder, at this case to phase 3 .

\section{System Working Results}

The above system working cases and others casese may be summerized in Table 2. That take in consederation differents inputs and give the right outputs after making the decision for each output coresponding of inputs. For proposed design system, if the range of input values (180 AC input volt and above) was considered as a right input, if the range input values (170 AC volt down to 60) was considered as a week inputs and if the range input values (50 AC volt down to 0 ) was considered as a cut inputs. All the above inputs ranges not constant and limited for this values only but may be change according to customer requrements.

\section{Conclusion and Idea for Future Work}

Through this work, it is possible to avoid the risk of weakness or cutting in one or more feeders which causes the continuity of the processing of electricity for all devices of the house safely, this leads to stability in the work of household electrical appliances and avoid the dangers for effects of turn off and on devices result increase its life. In addition to homes this system can be used in large applications such as sensitive places that require continuous processing of electrical power such as, all types of warehouses, hospital operation rooms, patients 
Citation: Jahlool JS (2018) Automatic Detection and Correction the Fault in Electrical Power Feeders Based Microcontroller. J Electr Electron Syst 7: 271. doi: $10.4172 / 2332-0796.1000271$

Page 5 of 6

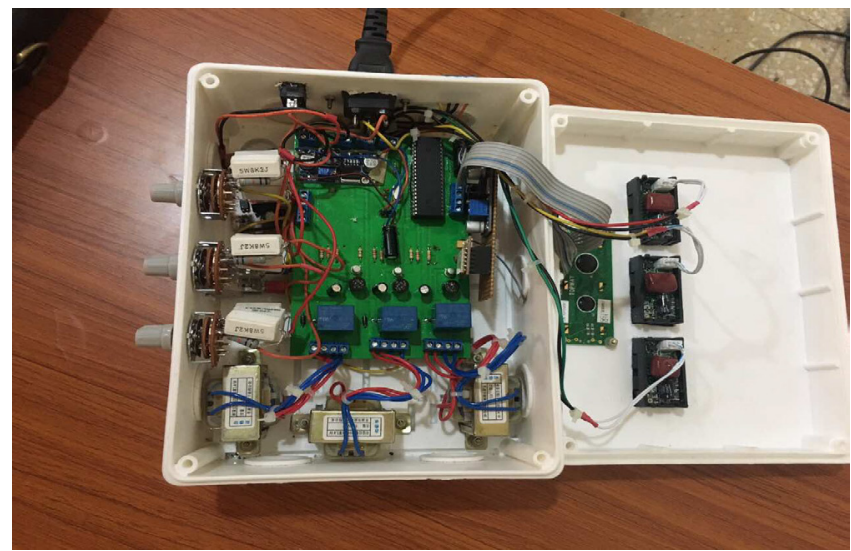

Figure 7: Prototype circuit.

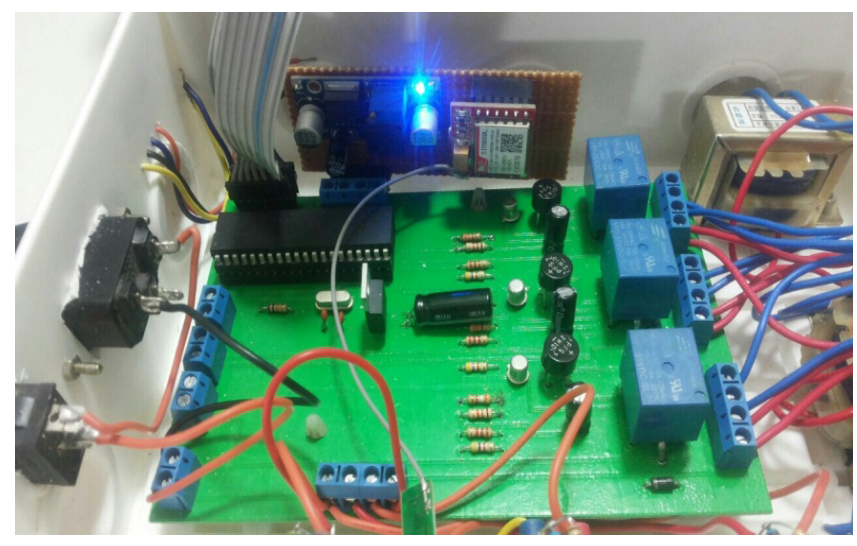

Figure 8: Printed boared circuit.

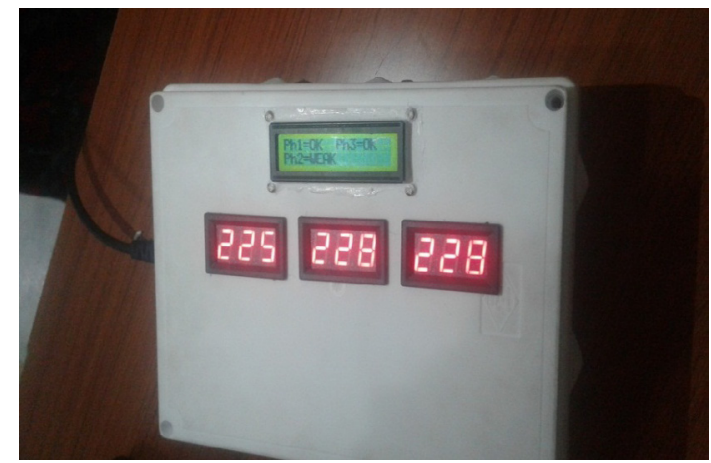

Figure 9: Sample of working case.

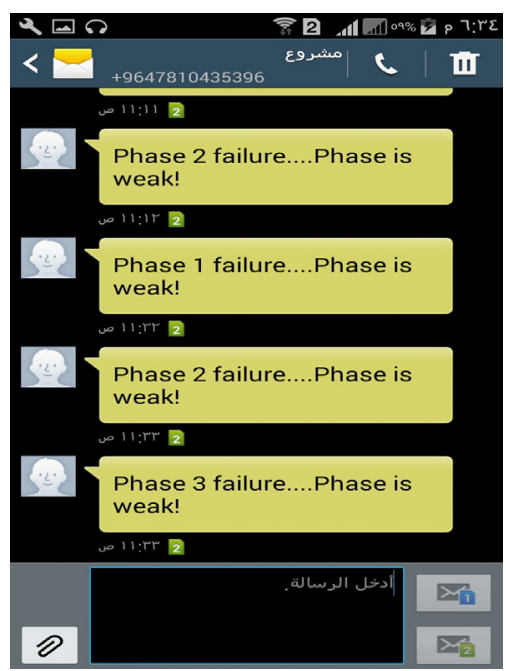

Figure 10: Sample of SMS message.

\begin{tabular}{|c|c|c|c|c|c|c|c|c|}
\hline $\begin{array}{c}\text { AC input } \\
\text { phase } 1\end{array}$ & $\begin{array}{c}\text { AC input } \\
\text { phase } 2\end{array}$ & $\begin{array}{c}\text { AC input } \\
\text { phase } 3\end{array}$ & $\begin{array}{c}\text { Output } \\
\text { phase } 1\end{array}$ & $\begin{array}{c}\text { Output } \\
\text { phase } 1\end{array}$ & $\begin{array}{c}\text { Output } \\
\text { phase } 3\end{array}$ & $\begin{array}{l}\text { Decision } \\
\text { phase } 1\end{array}$ & $\begin{array}{l}\text { Decision } \\
\text { phase } 2\end{array}$ & $\begin{array}{c}\text { Decision } \\
\text { phase } 3\end{array}$ \\
\hline 210 & 110 & 220 & 210 & 220 & 220 & ok & week & ok \\
\hline 220 & 0 & 200 & 220 & 200 & 200 & ok & cut & ok \\
\hline 180 & 220 & 190 & 180 & 220 & 190 & ok & ok & ok \\
\hline 160 & 210 & 170 & 210 & 210 & 210 & week & ok & week \\
\hline 140 & 180 & 150 & 180 & 180 & 180 & week & ok & week \\
\hline 120 & 160 & 100 & 0 & 0 & 0 & week & week & week \\
\hline 100 & 140 & 80 & 0 & 0 & 0 & week & week & week \\
\hline 80 & 120 & 60 & 0 & 0 & 0 & week & week & week \\
\hline 60 & 200 & 50 & 200 & 200 & 200 & week & ok & cut \\
\hline 10 & 10 & 10 & 0 & 0 & 0 & cut & cut & cut \\
\hline
\end{tabular}

Table 2: Differents A.C for the three phases (feeders) inputs, decision and right outputs.

devices with special needs as well as general uses such as offices, bankes, indisterials, factores, study halls and various workplaces. This system is very useful because they have good features like low power consumption, low cost, small size, simplicity and reliability in addition to all above facilities can be used for different places. In the future, there are several possible improvements can be made in order to upgrade the features be using a wireless connection to connect between the power part and MCU in order to place the device far from the effect of alternating current and voltage effects, this is the first point and the second point, the weakening voltage values and ranges may customize according to user requirements.

\section{References}

1. Song Y, Wang W, Zhang Z, Qi H, Liu Y (2017) Multiple Event Detection and Recognition for Large-Scale Power Systems Through Cluster-Based Sparse Coding. IEEE Trans Power Sys 32: 4199-4210.

2. Anusha S, Madhavi M, Hemalatha R (2014) Detection of Power Theft Using GSM. IJARTET 1: 15-17. 
Citation: Jahlool JS (2018) Automatic Detection and Correction the Fault in Electrical Power Feeders Based Microcontroller. J Electr Electron Syst 7: 271. doi: $10.4172 / 2332-0796.1000271$

Page 6 of 6

3. Patil DK, Avhad KG, Johore PC, Sharma MK (2017) A review paper om controlling of three phase and signale phase electrical equipment by using iot, gsm and wi-fi. Int J Res 5: 135-139.

4. Morales $\mathrm{COH}$, González JPN (2013) Fault Detection and Diagnosis of Electrical Networks Using a Fuzzy System and Euclidian Distance. MICAI, pp: 216-224.

5. Bunnoon P (2013) Fault Detection Approaches to Power System: State-of-the-
Art Article Reviews for Searching a New Approach in the Future. IJECE 3 : 553-560.

6. Sonwane ND, Dighe DD (2016) Fault Detection and Auto line Distribution System with GSM Module. IJRASET 4: 1764-1766.

7. SIM800L_Hardware_Design_V1.00. Shanghai SIMcom wireless solution Ltd. 2013. 